\title{
Googling Gold in Indonesia
}

\author{
Olivia Tanaya ${ }^{1}$, Suyanto $^{2}$ \\ \{oliviatanaya@staff.ubaya.ac.id ${ }^{1}$, suyanto@staff.ubaya.ac.id\}
}

Faculty of Business and Economics, University of Surabaya, Indonesia ${ }^{1}$, Faculty of Business and Economics, University of Surabaya, Indonesia ${ }^{2}$

\begin{abstract}
In this modern world, collecting information becomes easier and quicker. Google Search dominates the market worldwide as an important source of information. Despite the growing researches that try to utilize it as a tool to observe the behavior of population, researches in the commodity market are still rare. This research applies an autoregressive model and Granger causality to explores the relationship between investor attention (captured by Google Trend) and gold. Indonesia has the largest gold mine in the world and there is a growing trend from people to invest in gold especially through digital platforms. The number of people uses Google Search in Indonesia will support the exploration of investor attention. The result shows that when there is a positive return in gold, it will decrease search queries, vice versa. People treat gain and loss differently. In addition, google trend can be used as an instrument to forecast gold return.
\end{abstract}

Keywords: google trend, google search, investor attention, gold, Indonesia.

\section{Introduction}

Due to modern broadband connectivity, collecting information through internet search engine becomes easier and quicker. Today, Google Search is an important source of information. In May 2020, Google continues to dominate the market worldwide with market share around $92.06 \%$. In Indonesia, it even reached 97.98\% [1]. These statistics indicate that Google Search can be a source to observe internet behavior of population. Specifically, it is also revealed the attention of population [2]. For example: if we search for a tourism destination, we are indeed paying attention to this place. Google Trends, in here, is a platform that provides the number of searches in Google. By using Google Trend, we can trace how many people are interested with the subject.

Some researchers are trying to utilize the data from Google Trend such as for forecast stock returns [3], foreign market volatility [4], predict Italian youth unemployment rate [5]. Despite the growing literature which seeks to explore the impact of attention captured by Google trend, studies related to commodities are still rare. Especially, the majority of previous literature are about US market and the other developed market. This study wants to fill the gap by exploring the relationship of investor attention and gold return in Indonesia.

Indonesia has the largest gold mine in the world. It is located in the eastern Papua province and known as the Grasberg mine. According to United States Geological Survey, Indonesia produced up to $160,000,000 \mathrm{~kg}$ of gold in 2019, and almost half of it is produced in Grasberg. The desire to add gold in the investment portfolio also increased day by day. Although the majority of people still buy gold in the traditional way, but there is a growing trend from younger generations (especially millennials) to buy gold through digital platforms (digi-gold). 
Investment in digital platforms are attractive due to the benefits offered such as (1) In the traditional way, people need to have quite a big amount of initial capital if they want to buy gold. In digital platforms, they can start with a relatively small amount of money; (2) It is easy and simple, as long as we have an internet connection we can do the investment-trading activity; (3) It is safe. Some people afraid to invest in physical gold due to they do not have safe deposit box. Thus, it is risky for keeping gold.

The growing trend of digi-gold also supported by the recent situation that people are more likely to not have offline activity. They do not go to the place with a lot of people in it. In the future, we can imagine people will try to move their activity to fully online based due to their concern safety. Both collecting information and trading activity will be online. Here, the roles of Google as a platform to provide information will become bigger. The more activities occur in Google, it will provide a bigger frame to observe the behavior of the population.

This research contributes to the literature in several ways. First, it contributes to the literature in terms of the exploration of investor attention on the commodity market. Second, previous literature mainly focuses on developed countries. While this research background is in Indonesia, developing countries, it can provide a perspective of the behavior from developing countries. Last, it can be used as a tool to forecast gold return.

\section{Literature Review}

Investors gather information for their investment portfolios. It needs time and attention from investors to process and makes decisions from available information. Limited attention generates delays to investor's consumption and portfolio decisions [6]. The relationship between the implication of investor attention on financial assets is widely evident such as using public news on monthly stock return [7]. They finds that investors tend to react slowly on bad news. Twitter mood to predict stock market [8]. The accuracy of the stock market can be significantly improved by using specific public mood. It also helps to reduce percentage error. Firms whose information is available in Wikipedia are associated with smaller errors in the analyst forecast [9].

On the other hand, the impact of an asset on investor attention can be taken from behavior finance perspective. The decision under the risk is widely known as prospect theory. It is argued that people threats gain and losses differently. Essentially, losses cause a greater emotional impact on investors. Under the same result, the asymmetric situation makes people tend to pick the option with perceived gain [10]. People with gain in their task tend to decrease choice switching, therefore, a gain can promote calmness. On the other hand, losses produce restless effect. People with losses in their task tend to do more choice switching [11].

\section{Methodology and Data Analysis}

\subsection{Data and Variables}

Google inc. creates a website that analyzes top search queries in Google Search across various languages and regions. This website is known as Google Trend which compares the volume of the search queries over the time. Google provides features to filter the search query, such as by the region, by the time, categories of the search query, and also web search. In this study, we use the keyword "gold" (in Bahasa Indonesia: emas), and use a filter to limit the 
searches in Indonesia. The data for the price of gold is obtained from Goldprice.org and denoted in Indonesian Rupiah. Since the data from Google Trend is available starts from 2004, our sample consists of monthly data from January 2004 until May 2020.

\subsection{Method and Model}

For the first step of analysis, the data are checked by using Augmented Dickey Fuller (ADF). Second, we use Autoregressive model to analyze the relationship between Google Trend and gold. Last, Granger-causality test will be used to test the causality direction of the variables.

\subsubsection{Augmented Dickey Fuller}

The pre-requisite condition before applying any econometrics model is to check the stationary of data series. The importance to check the condition of the data is due to nonstationary series may bring a spurious result that leads to an incorrect conclusion. There are three models in the ADF test: (1) No constant and no trend; (2) Constant with no trend; (3) Constant and trend. The model needs to be chosen based on the graph of the data series.

\subsubsection{Autoregressive Model}

There are several models that we use to analyze. Model (1) examines the impact of changes in current search queries on gold return. Model (1) is stated below:

$$
r_{t}=\alpha_{0}+\alpha_{1} r_{t-1}+\alpha_{2} \Delta G T_{t}+\varepsilon_{t}
$$

Where $r_{t}$ is the log of gold return at time t, $\Delta G T_{t}$ is log of changes in Google Trend, and $\varepsilon_{t}$ is innovation term. In order to analyze the lagged of search queries, $\Delta G T_{t}$ is changed with $\Delta G T_{t-1}$ in the equation (1). This model becomes model (2).

In return, model (3) and (4) examines the effect of return on changes in Google Trend. The following model is use for model (3):

$$
\Delta G T_{t}=\alpha_{0}+\alpha_{1} \Delta G T_{t-1}+\alpha_{2} r_{t}+\varepsilon_{t}
$$

Model (4) is obtained by change current gold return $r_{t}$ by its lagged $r_{t-1}$ in the equation (2).

Further, this study explores the relationship between volatility of gold return and changes in search queries. Following previous research, the absolute return is used to observe the volatility of gold return [12]. Model (5) is given by:

$$
\left|r_{t}\right|=\alpha_{0}+\alpha_{1}\left|r_{t-1}\right|+\alpha_{2} \Delta G T_{t}+\varepsilon_{t}
$$

While for model (6) is obtained from changing $\Delta G T_{t}$ with $\Delta G T_{t-1}$ in the equation (3). Model (7) and (8) are analyzed by using absolute return in the equation (2).

We also consider the relationship between volatility of gold return and volatility in the search queries. The following model is use for model (9):

$$
\left|\Delta G T_{t}\right|=\alpha_{0}+\alpha_{1}\left|\Delta G T_{t-1}\right|+\alpha_{2}\left|r_{t}\right|+\varepsilon_{t} .
$$


The lagged of absolute gold return in the equation (4) becomes model (10). Last, for model (11) we examines the effect of volatility in the search queries on the volatility of gold return. Here is the equation for model (11):

$$
\left|r_{t}\right|=\beta_{0}+\beta_{1}\left|r_{t-1}\right|+\beta_{2}\left|\Delta G T_{t}\right|+\varepsilon_{t}
$$

Model (12), then is obtained by replacing the current changes in search queries to lagged changes in search queries.

\subsubsection{Granger Causality Test}

According to Granger (1969), X granger-cause Y if the past value of X can help to forecast the value of current $\mathrm{Y}$ [13]. If $\mathrm{X}$ does not cause $\mathrm{Y}$ and $\mathrm{Y}$ does not cause $\mathrm{X}$, it means that these variables are statistically independent. Granger causality will be used to examine the causality between gold return and changes in Google Trend.

\section{Research Result and Discussion}

\subsection{Findings of Unit Root Test}

From Table 1, it shows that gold price is non-stationary at level, but stationary at first difference. While for gold return, Google Trend, and changes in Google Trend, all of them are stationary at level. Since this study only uses gold return and changes in Google Trend in the model, hence there is no significant issue in terms of methodology.

Table 1 Unit root test results

\begin{tabular}{|c|c|c|c|c|}
\hline Level & Gold price & Gold return & $\begin{array}{l}\text { Google } \\
\text { Trend }\end{array}$ & $\begin{array}{c}\text { Changes in } \\
\text { Google Trend }\end{array}$ \\
\hline With constant & 0.4598 & $-14.7243 * * *$ & -1.0692 & $-11.9591 * * *$ \\
\hline With constant \& trend & -1.8166 & $-14.7568 * * *$ & $-3.9828 * *$ & $-11.9273 * * *$ \\
\hline Without constant \& trend & 2.9269 & $-13.936 * * *$ & 0.7102 & $-11.7659 * * *$ \\
\hline First Difference & Gold price & Gold return & $\begin{array}{l}\text { Google } \\
\text { Trend }\end{array}$ & $\begin{array}{c}\text { Changes in } \\
\text { Google Trend }\end{array}$ \\
\hline With constant & $-12.9681 * * *$ & $-8.8178 * * *$ & $-19.1873 * * *$ & $-11.0370 * * *$ \\
\hline With constant \& trend & $-12.9881 * * *$ & $-8.8154 * * *$ & $-19.1636^{* * * *}$ & $-11.0054 * * *$ \\
\hline Without constant \& trend & $-12.4752 * * *$ & $-9.7487 * * *$ & $-19.1271 * * *$ & $-11.0667 * * *$ \\
\hline
\end{tabular}

\subsection{Findings of Autoregression Results}

The autoregression results from Table 2 indicate there is negative relationship between the current and the lagged condition of gold return and changes in search queries. It means negative returns will increase search queries, while positive returns will decrease search queries. These 
findings support the concept of asymmetric behavior related to the changes in the commodity return. This result is in line with prospect theory that argue people threats gain and losses differently. Investors tend to react more to the losses than gain. The asymmetric behavior in the commodity return is similar with the situation in the stock market. The price movement is much larger during bad news than good news [14]. They argued that it could be due to leverage effect. Decline in the stock price make the debt and equity ratio becomes higher and lead to a higher risk. The risk from negative return cause a greater emotional impact on investors.

Table 2 Autoregressive results from model 1-4

\begin{tabular}{lcccc}
\hline & $(1)$ & $(2)$ & $(3)$ & $(4)$ \\
\hline $\mathrm{c}$ & $r_{t}$ & $r_{t}$ & $\Delta G T_{t}$ & $\Delta G T_{t}$ \\
$r_{t}$ & 0.0112 & $0.0088^{* *}$ & 0.0106 & 0.0113 \\
$r_{t-1}$ & -0.0721 & & -0.0007 & \\
$\Delta G T_{t}$ & -0.0095 & 0.1323 & & -0.0785 \\
$\Delta G T_{t-1}$ & & & & \\
\hline$r^{2}$ & 0.0057 & 0.0230 & -0.2425 & -0.2356 \\
\hline
\end{tabular}

Note: *** indicates $1 \%$ significant level, **5\% level, and * $10 \%$ level

While for model 6 (Table 3), there is a positive significant impact of current search queries on the volatility of gold. It indicates that the more information received by investor will generate more volatility in the gold trading. This finding is in contrast with classical rational expectation model that argues more information received by investor will reduce uncertainty and decrease the level of volatility. However, the process of collecting information require scarce resources such as time, effort, and attention. The amount of this scarce resources will be different for every investor, thus, it can lead infrequent investment decisions [4].

Table 3 Autoregressive results from model 5-8

\begin{tabular}{lcccc}
\hline & 5 & 6 & 7 & 8 \\
\hline $\mathrm{c}$ & $\left|r_{t}\right|$ & $\left|r_{t}\right|$ & $\Delta G T_{t}$ & $\Delta G T_{t}$ \\
$\Delta G T_{t}$ & $0.0395^{* * *}$ & $0.0215^{* * *}$ & 0.0213 & 0.0208 \\
$\Delta G T_{t-1}$ & -0.0146 & & & \\
$\left|r_{t}\right|$ & & $0.0237^{* *}$ & -0.2318 & -0.2492 \\
$\left|r_{t-1}\right|$ & & & -0.3393 & \\
\hline \multicolumn{1}{c}{$r^{2}$} & -0.2277 & $0.3234^{* *}$ & & -0.3191 \\
\hline
\end{tabular}

Note: *** indicates $1 \%$ significant level, ** 5\% level, and * $10 \%$ level

In model 7 and 8 (Table 3), it shows that the volatility of gold returns have negative impact on the Google Trend. Instability of gold return will reduce investor attention. When we carefully analyze the relationship of volatility gold return and volatility of Google Trend (model 9 and $10)$, it displays the volatility of gold return will cause volatility on Google Trend. This result is 
interesting, as previously people react differently in good and bad news, but the volatility in gold return still can cause volatility in the Google Trend. Last, from model 11 and 12 (Table 4), it shows there is a positive significant impact of the volatility in the Google Trend on volatility of gold return. It indicates that investor attention can help to predict the volatility of gold return.

Table 4 Autoregressive results from model 9-12

\begin{tabular}{|c|c|c|c|c|}
\hline & 9 & 10 & 11 & 12 \\
\hline & $\left|\Delta G T_{t}\right|$ & $\left|\Delta G T_{t}\right|$ & $\left|r_{t}\right|$ & $\left|r_{t}\right|$ \\
\hline $\mathrm{c}$ & $0.0412 *$ & $0.0592 *$ & $0.0308 * * *$ & $0.0236 * * *$ \\
\hline$\left|r_{t}\right|$ & $0.8160 * *$ & & & \\
\hline$\left|r_{t-1}\right|$ & & 0.4372 & -0.1276 & 0.2022 \\
\hline$\left|\Delta G T_{t}\right|$ & & & $0.0421 * *$ & \\
\hline$\left|\Delta G T_{t-1}\right|$ & $0.4686^{* *}$ & $0.4229 *$ & & 0.0153 \\
\hline$r^{2}$ & 0.3484 & 0.3335 & 0.0483 & 0.0135 \\
\hline
\end{tabular}

Note: *** indicates $1 \%$ significant level, ** 5\% level, and * $10 \%$ level

\subsection{Findings of Granger Causality Test}

The probability that gold return does not Granger cause changes in Google Trend is 0.1382 , therefore, the null hypothesis cannot be rejected. It means that in the short-run, gold return does not granger cause Google Trend. On the other hand, the null hypothesis that changes in Google Trend does not cause changes in gold return can be rejected as the probability from this test is 0.0381 or less than $5 \%$ significant level. From these results, we can conclude that the past value of Google Trend can forecast the value of gold return.

\section{Summary}

This study presents an analysis of the relationship of investor attention captured by Google Trend on gold return. Similar to the previous study, gain promotes calmness, while losses could cause restlessness [11]. When there is a positive return of gold, Indonesian investor tends to decrease search queries, on the contrary, negative return leads them to google more information. We also find that Google Trend has a positive and significant impact on the volatility of gold return. The different amounts of scarce resources such as attention, time, and effort cause infrequent investment decisions. Last, we find that Google Trend can be used as an instrument to predict the value of gold return. 


\section{References}

[1] GlobalStats, "Search Engine Market Share Indonesia," 2020. https://gs.statcounter.com/search-engine-market-share/all/indonesia (accessed Jun. 19, 2020).

[2] Z. Da, J. Engelberg, and P. Gao, "In Search of Attention," J. Finance, vol. 66, no. 5, pp. 1461-1499, Oct. 2011, doi: 10.1111/j.1540-6261.2011.01679.x.

[3] L. Bijl, G. Kringhaug, P. Molnár, and E. Sandvik, "Google searches and stock returns," Int. Rev. Financ. Anal., vol. 45, no. 0, pp. 150-156, 2016, doi: 10.1016/j.irfa.2016.03.015.

[4] J. Goddard, A. Kita, and Q. Wang, "Investor attention and FX market volatility," J. Int. Financ. Mark. Institutions Money, vol. 38, no. 0, pp. 79-96, 2015, doi: 10.1016/j.intfin.2015.05.001.

[5] A. Naccarato, S. Falorsi, S. Loriga, and A. Pierini, "Combining official and Google Trends data to forecast the Italian youth unemployment rate," Technol. Forecast. Soc. Change, vol. 130, no. 0, pp. 114-122, 2018, doi: 10.1016/j.techfore.2017.11.022.

[6] L. Peng, "Learning with Information Capacity Constraints," J. Financ. Quant. Anal., vol. 40, no. 2, pp. 307-329, 2005, doi: 10.1017/s0022109000002325.

[7] W. C. Chan, "Stock price reaction to news and no-news: Drift and reversal after headlines," J. financ. econ., vol. 70, no. 2, pp. 223-260, 2003, doi: 10.1016/S0304405X(03)00146-6.

[8] J. Bollen, H. Mao, and X. Zeng, "Twitter mood predicts the stock market," J. Comput. Sci., vol. 2, no. 1, pp. 1-8, 2011, doi: 10.1016/j.jocs.2010.12.007.

[9] A. Rubin and E. Rubin, "Informed investors and the internet," J. Bus. Financ. Account., vol. 37, no. 7-8, pp. 841-865, 2010, doi: 10.1111/j.1468-5957.2010.02187.x.

[10] D. Kahneman and A. Tversky, "Prospect theory: An analysis of decision under risk. Econometrika, 47, 263-291.," Econometrica, vol. 47, no. 2, pp. 263-292, 1979, doi: $10.2307 / 1914185$.

[11] E. Yechiam, G. Zahavi, and E. Arditi, "Loss restlessness and gain calmness: durable effects of losses and gains on choice switching," Psychon. Bull. Rev., vol. 22, no. 4, pp. 1096-1103, 2015, doi: 10.3758/s13423-014-0749-4.

[12] D. G. Baur and T. Dimpfl, "Googling gold and mining bad news," Resour. Policy, vol. 50, no. November, pp. 306-311, 2016, doi: 10.1016/j.resourpol.2016.10.013.

[13] C. W. Granger, "Investigating causal relations by econometric models and crossspectral methods. Econometrica," Econometrica, vol. 37, no. 3, pp. 424-438, 1969, doi: $10.2307 / 1912791$

[14] C. W. S. Chen, T. C. Chiang, and M. K. P. So, "Assymetrical reaction to US stockreturn news: Evidence from major stock markets based on a double-threshold model," J. Econ. Bus., vol. 55, no. 5-6, pp. 487-502, 2003, doi: 10.1016/S0148-6195(03)000511. 